\title{
Clinicopathological and prognostic significance of metastasis-associated protein 1 expression and its correlation with angiogenesis in lung invasive adenocarcinomas, based on the 2011 IASLC/ATS/ERS classification
}

\author{
SHUHAI LI, HUI TIAN, WEIMING YUE, LIN LI, CUN GAO, LIBO SI, WENSI HU, \\ LEI QI, MING LU, CHUANLE CHENG, JINGJING CUI and GUANQING CHEN \\ Department of Thoracic Surgery, Qilu Hospital, Shandong University, Jinan, Shandong 250012, P.R. China
}

Received November 24, 2014; Accepted October 5, 2015

DOI: 10.3892/ol.2015.3839

\begin{abstract}
Based on previous findings regarding the angiogenic activities and prognostic roles of metastasis-associated protein 1 (MTA1) in early-stage non-small cell lung cancer, the clinicopathological and prognostic significance of MTA1 protein expression, and its correlation with angiogenesis in lung invasive adenocarcinoma, were further assessed in the present study, according to the 2011 International Association for the Study of Lung Cancer/American Thoracic Society/European Respiratory Society classification. High protein expression levels of MTA1 were commonly observed in patients with lung invasive adenocarcinoma, and were significantly correlated with tumor size $(\mathrm{P}=0.030)$, lymph node metastasis $(\mathrm{P}=0.021)$ and microvessel density $(\mathrm{P}=0.015)$. Survival analysis demonstrated that patients with high protein expression levels of MTA1 exhibited significantly shorter five-year disease-free and overall survival than those patients whose protein expression levels of MTA1 were low (24.5\% vs. $48.7 \%, \mathrm{P}=0.001$, and $34.7 \%$ vs. $59.2 \%, \mathrm{P}=0.005$, respectively). In addition, Cox regression multivariate analysis demonstrated that high protein expression levels of MTA1 significantly correlated with unfavorable five-year disease-free survival $(\mathrm{P}=0.024)$. These findings indicate that MTA1 protein
\end{abstract}

Correspondence to: Professor Hui Tian, Department of Thoracic Surgery, Qilu Hospital, Shandong University, 107 Wen Hua Xi Lu, Jinan, Shandong 250012, P.R. China

E-mail: tianhuiql@126.com

Abbreviations: MTA1, metastasis-associated protein 1; IASLC/ATS/ERS, International Association for the Study of Lung Cancer/American Thoracic Society/European Respiratory Society; AIS, adenocarcinoma in situ; MIA, minimally invasive adenocarcinoma; NSCLC, non-small cell lung cancer; MVD, microvessel density

Key words: metastasis-associated protein 1, angiogenesis, microvessel density, prognosis, lung invasive adenocarcinoma expression may possess clinical potential as an indicator of progressive phenotype. Therefore, MTA1 is a promising prognostic predictor to identify subgroups of patients with high risk of relapse, and a potentially novel therapeutic target for antiangiogenesis in patients with lung invasive adenocarcinoma.

\section{Introduction}

Lung cancer is the most common malignancy and the leading cause of cancer-associated mortality worldwide (1-3). The incidence of adenocarcinoma has gradually increased in the past decades, and has become the most prevalent histological subtype of primary lung cancer worldwide (4-6). Lung adenocarcinoma is characterized by its diverse clinical, radiological, pathological, histological and molecular heterogeneity. This histological heterogeneity has led to modifications in the classification of lung adenocarcinoma $(7,8)$. According to the novel architectural classification of lung adenocarcinoma proposed by the International Association for the Study of Lung Cancer/American Thoracic Society/European Respiratory Society (IASLC/ATS/ERS) in 2011, the previous morphological classification of the different histological subtypes of lung adenocarcinoma has been substituted by a comprehensive multidisciplinary classification (9). According to this novel classification, patients with adenocarcinoma in situ (AIS) and minimally invasive adenocarcinoma (MIA) are expected to present favorable five-year survival, whereas the prognoses of patients with lung invasive adenocarcinomas, including those with pathological stage IA, are relatively poor (10-12). Clearly, a further understanding of the mechanisms underlying the pathogenesis and progression of lung invasive adenocarcinoma would promote the development of novel prognostic markers and therapeutic targets that may improve the treatments and clinical outcomes of patients with lung cancer $(13,14)$.

Metastasis-associated protein 1 (MTA1) has been identified as a critical regulator of the carcinogenesis and aggressiveness of a wide variety of human malignancies (15-19). Previous studies by Li et al (20) demonstrated that high protein expression levels of MTA1 are involved in tumor angiogenesis and unfavorable prognosis in patients 
with early-stage non-small cell lung cancer (NSCLC), and MTA1 acts as a proangiogenic factor by promoting the migration, invasion and angiogenesis of NSCLC cells in vitro (21), thus contributing to the aggressive biological behavior and metastatic propensity of this type of cancer. However, to the best of our knowledge, the clinicopathological and prognostic roles of MTA1 protein expression, and its correlation with angiogenesis in lung invasive adenocarcinoma, have not been investigated thus far.

To address these questions, the protein expression levels of MTA1 were analyzed in the present study, and its clinicopathological and prognostic significance, in addition to its angiogenic activity in lung invasive adenocarcinoma, were evaluated based on the 2011 IASLC/ATS/ERS classification of lung adenocarcinoma (9).

\section{Materials and methods}

Patients. Medical records were reviewed to identify patients with primary lung invasive adenocarcinoma who had undergone complete lobectomy and systematic mediastinal lymph node dissection consecutively between January 2006 and December 2008 at the Department of Thoracic Surgery of Qilu Hospital, Shandong University (Jinan, China). Patients who received preoperative adjuvant chemotherapy and/or radiotherapy, succumbed to perioperative complications or were not subjected to follow-up examinations were excluded from the study. A total of 125 patients were selected for the study. The histology slides of each patient enrolled in the study were reviewed independently by two pathologists, and the histological subtypes were classified according to the criteria proposed by the 2011 IASLC/ATS/ERS international multidisciplinary classification of lung adenocarcinoma (9). The pathological staging was determined based on the 7 th edition of the Union for International Cancer Control Tumor Node Metastasis classification of malignant tumors (22). Informed consent was obtained from all the individual participants included in the study. The present study was approved by the institutional review board of Qilu Hospital, Shandong University. The general clinicopathological characteristics of the patients are presented in Table I.

Follow-up. All patients were regularly followed up subsequently to surgery. The patients were recommended to attend follow-up visits every three months for the first two years following surgery, and every six months thereafter. The follow-up protocol consisted of physical examination, blood tests, sonography, chest radiography, computed tomography (CT), magnetic resonance imaging, whole body bone scans and positron emission tomography-CT scans, if necessary. Recurrent disease was confirmed by fine-needle aspiration or cytopathological diagnosis when clinically feasible. All patients were followed up until mortality or last day of follow-up. The deadline of follow-up was December 2013, and the median clinical follow-up time was 58 months (range, 16-90 months).

Evaluation of MTAl protein expression and microvessel density (MVD). Immunohistochemical staining for MTA1 and cluster of differentiation (CD)105 was performed using an immunohistochemical detection kit (cat no. SP-9000; ZSGB-BIO, Beijing, China) according to the procedure previously described $(20,23)$, using a goat anti-human polyclonal antibody against MTA1 (sc-9446; Santa Cruz Biotechnology, Inc., Dallas, TX, USA) and a rabbit anti-human polyclonal antibody against CD105 (sc-20632; Santa Cruz Biotechnology, Inc.), respectively. The slides were incubated at $60^{\circ} \mathrm{C}$ for $30 \mathrm{~min}$, and deparaffinized in xylene, followed by rehydration with graded alcohol. Antigen retrieval was performed in citrate buffer for 15 min using a microwave oven. Once cooled down to room temperature, the slides were immersed in $3 \%$ hydrogen peroxide for $10 \mathrm{~min}$, and incubated in blocking serum for $30 \mathrm{~min}$ to reduce nonspecific binding. Upon discarding any excess of blocking solution, primary goat anti-MTA1 polyclonal antibody (1:100) and rabbit anti-CD105 polyclonal antibody (1:100) were applied to the slides, and incubated overnight at $4^{\circ} \mathrm{C}$. Next, the slides were incubated at $37^{\circ} \mathrm{C}$ for $30 \mathrm{~min}$ with biotinylated antibodies and streptavidin-peroxidase complex, followed by the addition of 3,3'-diaminobenzidine solution to visualize the staining corresponding to antibody-specific binding. Subsequently, the slides were counterstained with hematoxylin (ZLI-9609; ZSGB-BIO), and mounted with neutral balsam.

Semiquantitative determination of MTA1 protein expression was performed based on the staining intensity, as follows: i) A value of 0 was assigned to negative staining; ii) a score of 1 was assigned to weak staining; iii) 2 indicated moderate staining; and 3, intense staining. The proportion of positively stained cancer cells was $0,0 \sim 5 \% ; 1,6 \sim 25 \%$; $2,26 \sim 50 \% ; 3,51 \sim 75 \%$; and $4, \geq 76 \%$. The sum of the scores corresponding to the staining intensity and the percentage of positively stained cells was used to classify the different cases, and those tumors that displayed a final staining score of $\geq 4$ were defined as exhibiting high protein expression levels of MTA1.

CD105 was observed to be expressed in the cytoplasm and membrane of endothelial cells, and the MVD count was performed as previously described $(23,24)$. Briefly, the number of $\mathrm{CD} 105^{+}$microvessels was counted in a $\mathrm{x} 200$ microscopic field, and the mean value of the microvessels counted in five different vascular 'hot spots' was regarded as the final value for each case. All the immunostained slides were independently evaluated by two pathologists blinded to the clinicopathological and prognostic information of the patients. If disagreement emerged on the same slide, the reviewers would together use a multihead microscope, and discussed until a consensus score was achieved.

Statistical analysis. All data was statistically analyzed with SPSS statistical software version 18.0 (SPSS Inc., Chicago, IL, USA). The $\chi^{2}$ test was used to examine the association between the protein expression levels of MTA1 and the clinicopathological characteristics of the patients. The correlation between the protein expression levels of MTA1 and intratumoral MVD was analyzed by the nonparametric Mann-Whitney U test. Survival curves were plotted by the Kaplan-Meier method, and survival differences were compared by the log-rank test. Multivariate analysis was performed to identify significantly independent prognostic factors. $\mathrm{P}<0.05$ was considered to indicate a statistically significant difference. 
Table I. Correlation between the protein expression levels of MTA1 and the clinicopathological factors of the patients.

\begin{tabular}{|c|c|c|c|c|}
\hline \multirow[b]{2}{*}{ Variables } & \multirow[b]{2}{*}{ No. of patients } & \multicolumn{2}{|c|}{ MTA1 protein expression levels } & \multirow[b]{2}{*}{ P-value } \\
\hline & & Low & High & \\
\hline Gender & & & & 0.758 \\
\hline Man & 54 & 32 & 22 & \\
\hline Woman & 71 & 44 & 27 & \\
\hline Age (years) & & & & 0.204 \\
\hline$<60$ & 55 & 30 & 25 & \\
\hline$\geq 60$ & 70 & 46 & 24 & \\
\hline Histological subtypes & & & & 0.351 \\
\hline Lepidic & 13 & 10 & 3 & \\
\hline Acinar & 15 & 11 & 4 & \\
\hline Papillary & 51 & 28 & 23 & \\
\hline Solid & 35 & 19 & 16 & \\
\hline Micropapillary & 11 & 8 & 3 & \\
\hline Differentiation & & & & 0.978 \\
\hline Well & 37 & 23 & 14 & \\
\hline Moderate & 55 & 33 & 22 & \\
\hline Poor & 33 & 20 & 13 & \\
\hline Pleural invasion & & & & 0.819 \\
\hline Absent & 52 & 31 & 21 & \\
\hline Present & 73 & 45 & 28 & \\
\hline Tumor size (cm) & & & & 0.030 \\
\hline$\leq 3$ & 61 & 43 & 18 & \\
\hline$>3$ & 64 & 33 & 31 & \\
\hline Lymph node metastasis & & & & 0.021 \\
\hline Absent & 67 & 47 & 20 & \\
\hline Present & 58 & 29 & 29 & \\
\hline Pathological stage & & & & 0.054 \\
\hline I & 64 & 45 & 19 & \\
\hline II & 40 & 22 & 18 & \\
\hline III & 21 & 9 & 12 & \\
\hline
\end{tabular}

${ }^{\mathrm{a}}, \chi^{2}$ test; MAT1, metastasis-associated protein 1.

\section{Results}

Correlation between MTA1 protein expression and clinicopathological factors. Immunohistochemical analysis revealed positive immunostaining for MTA1 in the nuclei of the cancer cells, and different immunoreactivity for MTA1 protein was detected in regards to the percentage of positive cells stained and the intensity of the nuclear staining (Fig. 1A and B). Of the 125 primary lung invasive adenocarcinoma specimens analyzed, high protein expression levels of MTA1 were detected in 49 cases, and the association between the protein expression levels of MTA1 and the clinicopathological characteristics of the patients was analyzed by the $\chi^{2}$ test. As indicated in Table I, high protein expression levels of MTA1 were significantly correlated with the size of the tumor $(\mathrm{P}=0.030)$ and lymph node metastasis $(\mathrm{P}=0.021)$, whereas no significant differences were detected among the protein expression levels of MTA1 on the basis of the patients' gender $(\mathrm{P}=0.758)$, age $(\mathrm{P}=0.204)$, histological subtypes $(\mathrm{P}=0.351)$, differentiation $(\mathrm{P}=0.978)$, pleural invasion $(\mathrm{P}=0.819)$ and pathological stage $(\mathrm{P}=0.054$, which may be considered borderline significance).

Correlation between MTA1 protein expression and tumor angiogenesis. Intratumoral MVD was quantified by counting the number of $\mathrm{CD} 105^{+}$endothelial cells present in the cancer tissues (Fig. 1C). The staining intensity of MVD varied from 6.6 to 49.6 , with a median of 32.2/high power field (HPF). Double-staining of MTA1 and CD105 in the same serial sections of cancer tissues revealed that low protein expression levels of MTA1 were generally associated with few microvessels (6.6-49.4; median, 29.3/HPF), whereas high protein expression levels of MTA1 were generally associated with abundant microvessels (9.0-49.6; median, 37.0/HPF). Statistical analysis further demonstrated a significantly higher 
A

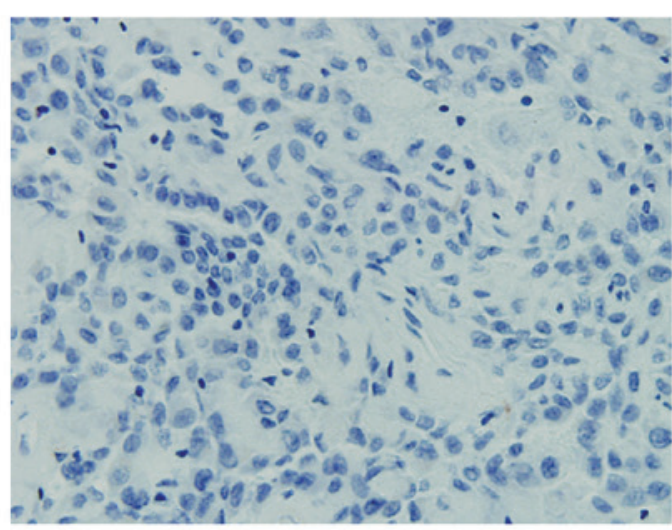

B

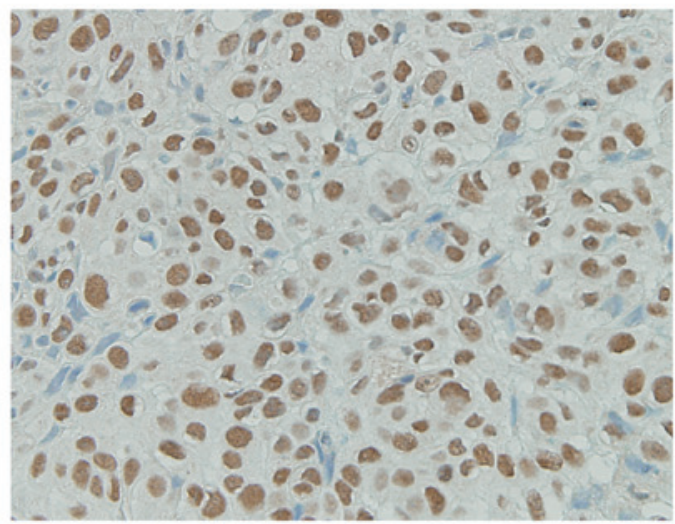

C

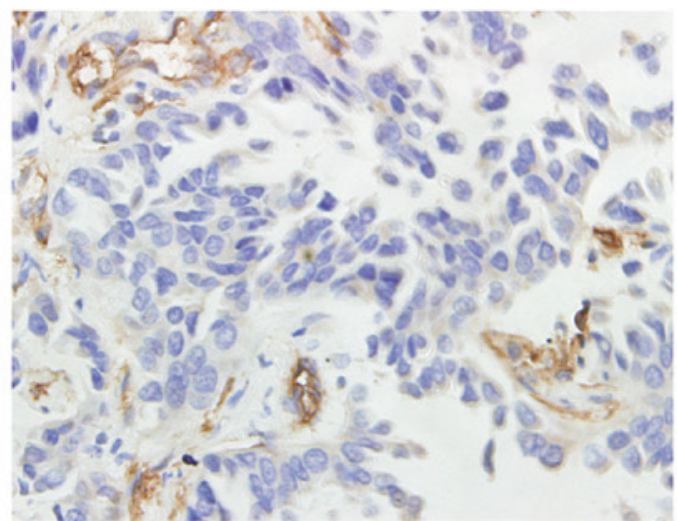

Figure 1. Immunohistochemical staining of lung invasive adenocarcinoma specimens, displaying (A) low and (B) high protein expression levels of metastasis-associated protein 1, respectively. (C) Intratumoral microvessels were immunopositive for cluster of differentiation 105 (magnification, x200)

MVD in tumors with high protein expression levels of MTA1 than in those with low protein expression levels of MTA1 ( $\mathrm{P}=0.015$, Mann-Whitney U test; Fig. 2).

Follow-up results and analysis of prognostic factors. During the follow-up period, tumor relapse developed in 76 patients (60.8\%), and 63 patients $(50.4 \%)$ succumbed to the disease. The median survival time of the subgroup of patients exhibiting high protein expression levels of MTA1 was 48.0 months, while the median survival time of the subgroup of patients displaying low protein expression levels of MTA1 was 61.5 months. As indicated in Table II, the results of the log-rank test demonstrated that the protein expression levels of MTA1 were significantly associated with the five-year disease-free survival

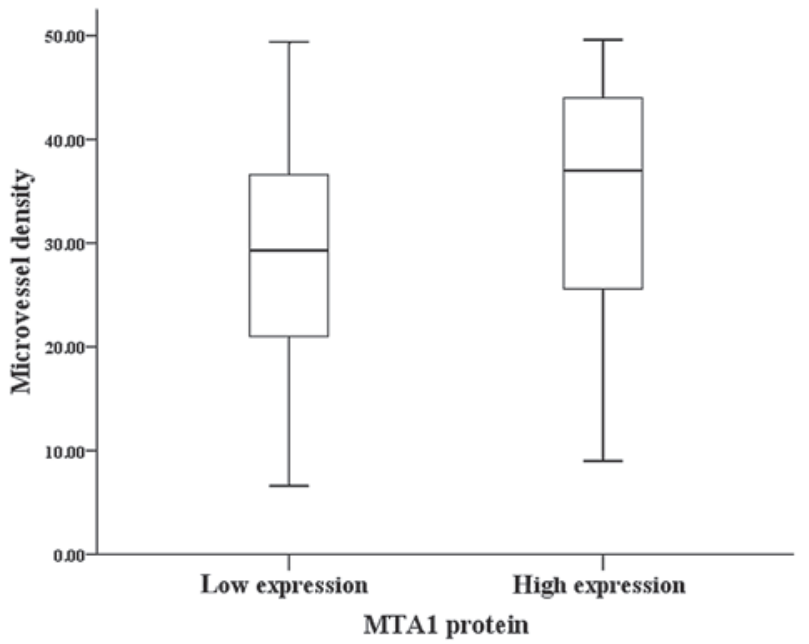

Figure 2. Mann-Whitney U test demonstrated that tumors with high protein expression levels of MTA1 exhibited significantly higher intratumoral microvessel density than tumors with low protein expression levels of MTA1 $(\mathrm{P}=0.015)$. MTA1, metastasis-associated protein 1 .

( $\mathrm{P}=0.001$; Fig. 3A). Other parameters such as tumor size, lymph node metastasis and pathological stage were also observed to be significantly associated with five-year disease-free survival $(\mathrm{P}<0.001)$. Furthermore, the protein expression levels of MTA1 were significantly associated with the five-year overall survival ( $\mathrm{P}=0.005$; Fig. 3B), in addition to tumor size, lymph node metastasis and pathological stage $(\mathrm{P}<0.001)$. The significantly independent prognostic factors were further analyzed by a multivariate Cox regression model, and the results indicated that MTA1 protein expression, tumor size, lymph node metastasis and pathological stage were independent prognostic factors for five-year disease-free survival $(\mathrm{P}=0.024,0.044$, 0.029 and 0.001 , respectively), whereas only the pathological stage $(\mathrm{P}=0.028)$ was identified as a significantly independent prognostic factor for five-year overall survival.

\section{Discussion}

Major advances in the treatment of lung adenocarcinoma are the result of the combined therapy that is currently administered to patients with lung cancer. This combined therapy consists of surgical resection, chemotherapy, radiotherapy and molecular targeting agents based on epidermal growth factor receptor (EGFR) (8). However, due to the high heterogeneity of lung adenocarcinoma, the overall five-year survival of patients affected by this disease is $<30 \%(25-28)$. This heterogeneity has led to modifications in the histological categories employed to classify the different types of lung adenocarcinoma, as described in the 2011 IASLC/ATS/ERS classification of lung adenocarcinoma (9). According to this novel classification, patients with AIS and MIA present favorable five-year disease-free survival, whereas the prognoses of patients with lung invasive adenocarcinoma, including those with pathological stage IA, are relatively poor $(11,12,29)$. The aim of the present study was to further investigate the underlying mechanisms involved in the invasive ability and metastatic properties of lung invasive adenocarcinoma, and to identify possible targets for novel treatments, including 
Table II. Results of univariate and multivariate survival analyses.

\begin{tabular}{|c|c|c|c|c|c|c|}
\hline \multirow[b]{3}{*}{ Variables } & \multicolumn{3}{|c|}{ Disease-free survival } & \multicolumn{3}{|c|}{ Overall survival } \\
\hline & \multirow{2}{*}{$\begin{array}{c}\text { Univariate analysis } \\
\text { P-value }\end{array}$} & \multicolumn{2}{|c|}{ Multivariate analysis } & \multirow{2}{*}{$\begin{array}{c}\text { Univariate analysis } \\
\text { P-value }\end{array}$} & \multicolumn{2}{|c|}{ Multivariate analysis } \\
\hline & & $95 \% \mathrm{CI}$ & P-value & & $95 \% \mathrm{CI}$ & P-value \\
\hline Gender & 0.893 & $0.549-1.494$ & 0.699 & 0.956 & $0.528-1.545$ & 0.710 \\
\hline Age & 0.664 & $0.745-2.060$ & 0.409 & 0.304 & $0.676-2.023$ & 0.575 \\
\hline Histological subtypes & 0.172 & $0.973-1.517$ & 0.086 & 0.221 & $0.956-1.525$ & 0.114 \\
\hline Differentiation & 0.087 & $0.975-1.819$ & 0.072 & 0.075 & $0.961-1.900$ & 0.083 \\
\hline Pleural invasion & 0.374 & $0.622-2.047$ & 0.690 & 0.279 & $0.602-2.227$ & 0.660 \\
\hline Tumor size & $<0.001$ & $1.017-3.809$ & 0.044 & $<0.001$ & $0.883-3.893$ & 0.103 \\
\hline Lymph node metastasis & $<0.001$ & $0.112-0.888$ & 0.029 & $<0.001$ & $0.268-2.350$ & 0.676 \\
\hline Pathological stage & $<0.001$ & $1.682-6.686$ & 0.001 & $<0.001$ & $1.088-4.368$ & 0.028 \\
\hline MTA1 protein levels & 0.001 & $1.076-2.899$ & 0.024 & 0.005 & $0.773-2.256$ & 0.309 \\
\hline
\end{tabular}

CI, confidence interval; MTA1, metastasis-associated protein 1.

A

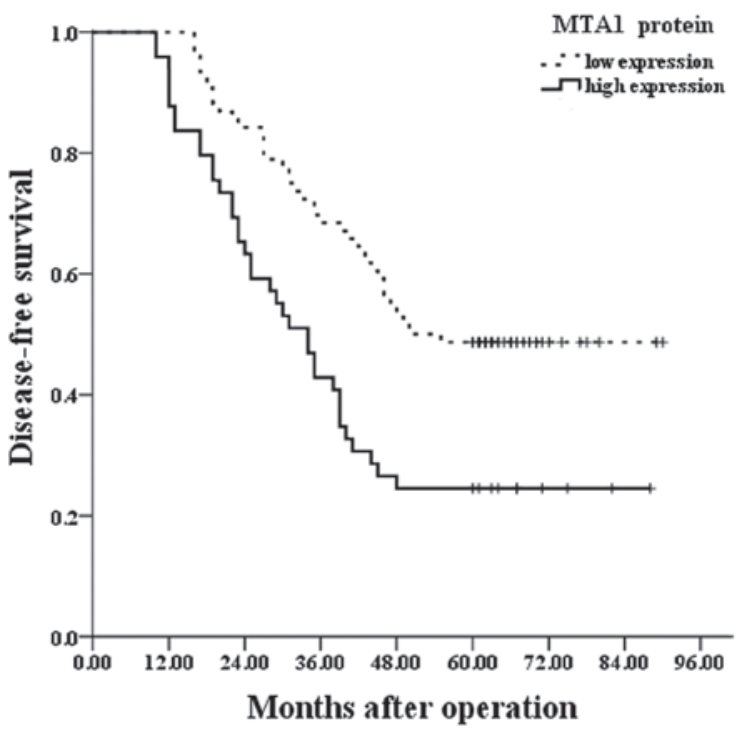

B

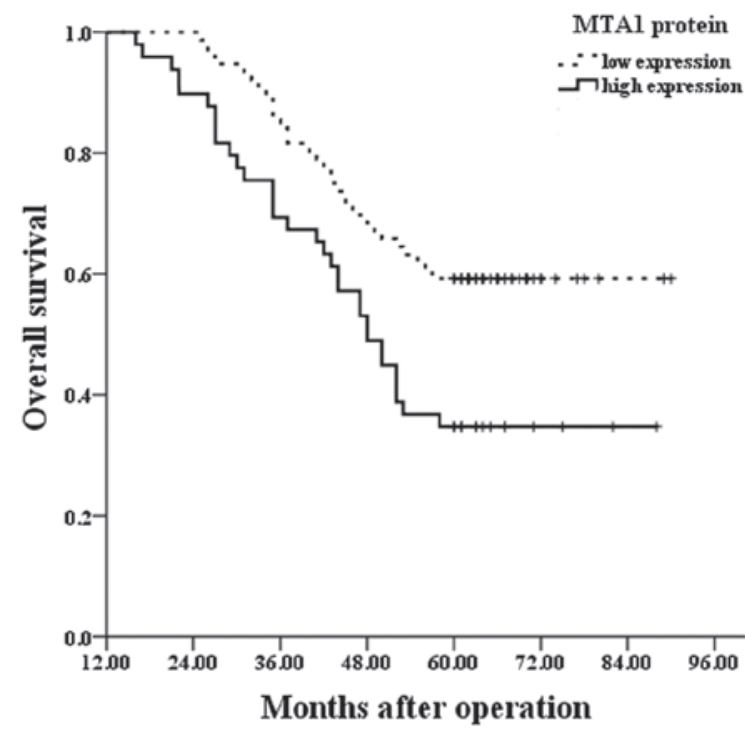

Figure 3. Kaplan-Meier curves of (A) disease-free and (B) overall survival, stratified according to the protein expression levels of MTA1. Log-rank test demonstrated that patients with high protein expression levels of MTA1 exhibited significantly shorter five-year disease-free and overall survival than those with low protein expression levels of MTA1 ( $24.5 \%$ vs. $48.7 \%, \mathrm{P}=0.001$, and $34.7 \%$ vs. $59.2 \%, \mathrm{P}=0.005$, respectively). MTA1, .metastasis-associated protein 1 .

individualized therapy, which may improve the clinical outcomes of patients with this type of cancer.

MTA1 is a component of the nucleosome remodeling and histone deacetylation complex, which functions in histone deacetylation, alteration of chromatin structure and control of transcription $(30,31)$. As a vital regulator, MTA1 has been observed to be aberrantly expressed in various human malignant tumors, and its expression levels are positively correlated with aggressive phenotypes characterized by their invasiveness and metastatic potential (15). Thus, MTA1 may be a target for overcoming tumor progression $(15,17)$. The association between MTA1 expression, angiogenesis and unfavorable prognosis in patients with early-stage NSCLC has been previously reported (20). Thus, it is clinically required to further assess the protein expression levels of MTA1 and analyze its clinicopathological and prognostic significance in human lung invasive adenocarcinoma. A total of 125 patients with primary lung invasive adenocarcinoma were enrolled in the present study, which aimed to elucidate the angiogenic activities and the clinicopathological and prognostic significance of MTA1 protein expression. The results revealed that high protein expression levels of MTA1 were significantly associated with tumor size and lymph node metastasis, and markedly associated with pathological stage, all factors known to contribute to aggressive phenotypes.

Antiangiogenesis is a pivotal strategy for treating malignancies (32), and MTA1 has been defined as a proangiogenic factor $(15,21,33,34)$. A previous study demonstrated that high intratumoral protein expression levels of MTA1 were significantly associated with angiogenesis in NSCLC (20). 
In addition, RNA interference-mediated downregulation of MTA1 protein expression in the lung adenocarcinoma cell line 95D was able to substantially inhibit the formation of capillary tube-like structures in vitro (21). However, the correlation of MTA1 protein expression with tumor angiogenesis in lung invasive adenocarcinoma has not been investigated thus far. In the present study, the expression of CD105, a homodimeric cell membrane glycoprotein, was evaluated in order to quantify tumor angiogenesis, since this marker is able to discriminate immature neovascularization from mature and established blood vessels $(35,36)$, thus indicating the presence of active angiogenesis in the tumor (37-39). The results demonstrated that high protein expression levels of MTA1 were significantly associated with increased angiogenic activity, as measured by the number of CD105-associated intratumoral microvessels, suggesting that MTA1 may be involved in tumor progression by participating in the process of angiogenesis in lung invasive adenocarcinoma. Tumor angiogenesis is a complex process, and the mechanism by which MTA1 modulates angiogenesis remains unknown (22,30-34). Therefore, further studies are required in order to elucidate the mechanisms by which MTA1 induces angiogenesis.

With regard to prognosis, the results of the univariate survival analysis conducted in the present study demonstrated that patients with high protein expression levels of MTA1 presented a significantly shorter five-year disease-free and overall survival than those patients with low protein expression levels of MTA1. Subsequent multivariate analysis demonstrated that high protein expression levels of MTA1 were an independent prognostic factor for unfavorable disease-free survival, but not for overall survival. Clinically, the long-term survival of patients with cancer may be influenced by multiple factors, including postoperative chemotherapy with different regimens and cycles, radiotherapy and EGFR-tyrosine kinase inhibitor therapy, which may cause statistical bias, thus resulting in the inability to objectively and adequately evaluate the prognostic significance of MTA1. Nevertheless, the subgroup of patients with high protein expression levels of MTA1 may require further oncologic evaluation and clinical attention following surgical resection than those patients with low protein expression levels of MTA1, due to their higher risk of relapse.

Taken together, the results of the present study demonstrated for the first time that aberrantly high protein expression levels of MTA1 are involved in the malignant phenotype and unfavorable prognoses of patients with lung invasive adenocarcinoma, possibly due to its potent angiogenic activity. However, the stepwise progression and facilitated neoangiogenesis is too complicated to be clearly elucidated by a simple clinical study like the present one. Therefore, future studies will contribute to a further understanding of the underlying mechanisms targeting MTA1, and provide a greater insight into the aggressive phenotype of lung invasive adenocarcinoma, which may aid the design of novel drugs targeting MTA1 and the development of more efficient antiangiogenic therapies aimed to improve the survival of certain subgroups of patients affected by lung cancer.

\section{Acknowledgements}

The present study was supported by the Independent Innovation Foundation of Shandong University (Jinan, China) (grant no. 2012DX005) and the National Natural Science Foundation of China (Beijing, China) (grant no. 81301832).

\section{References}

1. Jemal A, Bray F, Center MM, Ferlay J, Ward E and Forman D: Global cancer statistics. CA Cancer J Clin 61: 69-90, 2011.

2. Siegel R, Naishadham D and Jemal A: Cancer statistics, 2012. CA Cancer J Clin 62: 10-29, 2012.

3. Scarpa A, Sikora K, Fassan M, et al: Molecular typing of lung adenocarcinoma on cytological samples using a multigene next generation sequencing panel. PLoS One 8: e80478, 2013.

4. Fan $\mathrm{Z}$ and Schraeder R: The changing pathology of lung cancer. Surg Oncol Clin N Am 20: 637-653, 2011.

5. Bremer RE, Scoggin TS, Somers EB, O'Shannessy DJ and Tacha DE: Interobserver agreement and assay reproducibility of folate receptor $\alpha$ expression in lung adenocarcinoma: A prognostic marker and potential therapeutic target. Arch Pathol Lab Med 137: 1747-1752, 2013.

6. Sunaga N, Kaira K, Tomizawa Y, et al: Clinicopathological and prognostic significance of interleukin-8 expression and its relationship to KRAS mutation in lung adenocarcinoma. Br J Cancer 110: 2047-2053, 2014

7. Shim HS, Lee da H, Park EJ and Kim SH: Histopathologic characteristics of lung adenocarcinomas with epidermal growth factor receptor mutations in the International Association for the Study of Lung Cancer/American Thoracic Society/European Respiratory Society lung adenocarcinoma classification. Arch Pathol Lab Med 135: 1329-1334, 2011.

8. Shimada Y, Saji H, Nomura M, Matsubayashi J, Yoshida K, Kakihana M, Kajiwara N, Ohira T and Ikeda N: Cancer stem cell-related marker expression in lung adenocarcinoma and relevance of histologic subtypes based on IASLC/ATS/ERS classification. Onco Targets Ther 6: 1597-1604, 2013.

9. Travis WD, Brambilla E, Noguchi M, Nicholson AG, Geisinger KR, Yatabe Y, Beer DG, Powell CA, Riely GJ, Van Schil PE, et al: International association for the study of lung cancer/american thoracic society/european respiratory society international multidisciplinary classification of lung adenocarcinoma. J Thorac Oncol 6: 244-285, 2011.

10. Maeda R, Yoshida J, Ishii G, Hishida T, Nishimura M and Nagai K: Prognostic impact of histology on early-stage non-small cell lung cancer. Chest 140: 135-145, 2011.

11. Zhang J, Wu J, Tan Q, Zhu L and Gao W: Why do pathological stage IA lung adenocarcinomas vary from prognosis? A clinicopathologic study of 176 patients with pathological stage IA lung adenocarcinoma based on the IASLC/ATS/ERS classification. J Thorac Oncol 8: 1196-1202, 2013.

12. Ha SY and Roh MS: The new 2011 international association for the study of lung cancer/american thoracic society/european respiratory society classification of lung adenocarcinoma in resected specimens: Clinicopathologic relevance and emerging issues. Korean J Pathol 47: 316-325, 2013.

13. Cagle PT and Chirieac LR: Advances in treatment of lung cancer with targeted therapy. Arch Pathol Lab Med 136: 504-509, 2012.

14. Huang JY, Cui SY, Chen YT, Song HZ, Huang GC, Feng B, Sun M, De W, Wang R and Chen LB: MicroRNA-650 was a prognostic factor in human lung adenocarcinoma and confers the docetaxel chemoresistance of lung adenocarcinoma cells via regulating Bcl-2/Bax expression. PLoS One 8: e72615, 2013.

15. Toh Y and Nicolson GL: The role of the MTA family and their encoded proteins in human cancers: Molecular functions and clinical implications. Clin Exp Metastasis 26: 215-227, 2009.

16. Li Y, Chao Y, Fang Y, et al: MTA1 promotes the invasion and migration of non-small cell lung cancer cells by downregulating miR-125b. J Exp Clin Cancer Res 32: 33, 2013.

17. Wang H, Fan L, Wei J, et al: Akt mediates metastasis-associated gene 1 (MTA1) regulating the expression of E-cadherin and promoting the invasiveness of prostate cancer cells. PLoS One 7: e46888, 2012.

18. Zhou H, Xu X, Xun Q, et al: microRNA-30c negatively regulates endometrial cancer cells by targeting metastasis-associated gene-1. Oncol Rep 27: 807-812, 2012.

19. Song Q, Li Y, Zheng X, Fang Y, Chao Y, Yao K and Zhu X: MTA1 contributes to actin cytoskeleton reorganization and metastasis of nasopharyngeal carcinoma by modulating Rho GTPases and Hedgehog signaling. Int J Biochem Cell Biol 45: 1439-1446, 2013. 
20. Li SH, Tian H, Yue WM, Li L, Li WJ, Chen ZT, Hu WS, Zhu YC and Qi L: Overexpression of metastasis-associated protein 1 is significantly correlated with tumor angiogenesis and poor survival in patients with early-stage non-small cell lung cancer. Ann Surg Oncol 18: 2048-2056, 2011.

21. Li S, Tian H, Yue W, Li L, Gao C, Si L, Li W, Hu W, Qi L and Lu M: Down-regulation of MTA1 protein leads to the inhibition of migration, invasion and angiogenesis of non-small-cell lung cancer cell line. Acta Biochim Biophys Sin (Shanghai) 45: 115-122, 2013.

22. Rami-Porta R, Crowley JJ and Goldstraw P: The revised TNM staging system for lung cancer. Ann Thorac Cardiovasc Surg 15: 4-9, 2009.

23. Deng X, Du L, Wang C, Yang Y, Li J, Liu H, Zhang J, Wang L, Zhang X, Li W, et al: Close association of metastasis-associated protein 1 overexpression with increased angiogenesis and poor survival in patients with histologically node-negative gastric cancer. World J Surg 37: 792-798, 2013.

24. Vermeulen PB, Gasparini G, Fox SB, Colpaert C, Marson LP, Gion M, Beliën JA, de Waal RM, Van Marck E, Magnani E, et al: Second international consensus on the methodology and criteria of evaluation of angiogenesis quantification in solid human tumours. Eur J Cancer 38: 1564-1579, 2002.

25. Xu C, Gui Q, Chen W, Wu L, Sun W, Zhang N, Xu Q, Wang J and Fu X: Small interference RNA targeting tissue factor inhibits human lung adenocarcinoma growth in vitro and in vivo. J Exp Clin Cancer Res 30: 63, 2011.

26. Ma Q, Li P, Xu M, Yin J, Su Z, Li W and Zhang J: Ku80 is highly expressed in lung adenocarcinoma and promotes cisplatin resistance. J Exp Clin Cancer Res 31: 99, 2012.

27. Kauffmann M, Krüger T and Aebert H: Surgery on extracorporeal circulation in early and advanced non-small cell lung cancer. Thorac Cardiovasc Surg 61: 103-108, 2013.

28. Huang J, Song H, Liu B, Yu B, Wang R and Chen L: Expression of Notch-1 and its clinical significance in different histological subtypes of human lung adenocarcinoma. J Exp Clin Cancer Res 32: 84, 2013.

29. Yoshizawa A, Motoi N, Riely GJ, Sima CS, Gerald WL, Kris MG Park BJ, Rusch VW and Travis WD: Impact of proposed IASLC/ATS/ERS classification of lung adenocarcinoma: Prognostic subgroups and implications for further revision of staging based on analysis of 514 stage I cases. Mod Pathol 24: 653-664, 2011.

30. Zhang Y, Ng HH, Erdjument-Bromage H, Tempst P, Bird A and Reinberg D: Analysis of the NuRD subunits reveals a histone deacetylase core complex and a connection with DNA methylation. Genes Dev 13: 1924-1935, 1999.
31. Manavathi B, Peng S, Rayala SK, Talukder AH, Wang MH, Wang RA, Balasenthil S, Agarwal N, Frishman LJ and Kumar R: Repression of Six 3 by a corepressor regulates rhodopsin expression. Proc Natl Acad Sci USA 104: 13128-13133, 2007.

32. Hanahan D and Weinberg RA: Hallmarks of cancer: The next generation. Cell 144: 646-674, 2011.

33. Jang KS, Paik SS, Chung H, Oh YH and Kong G: MTA1 overexpression correlates significantly with tumor grade and angiogenesis in human breast cancers. Cancer Sci 97: 374-379, 2006.

34. Kai L, Wang J, Ivanovic M, Chung YT, Laskin WB, Schulze-Hoepfner F, Mirochnik Y, Satcher RL Jr and Levenson AS: Targeting prostate cancer angiogenesis through metastasis-associated protein 1 (MTA1). Prostate 71: 268-280, 2011.

35. Minhajat R, Mori D, Yamasaki F, Sugita Y, Satoh T and Tokunaga O: Organ-specific endoglin (CD105) expression in the angiogenesis of human cancers. Pathol Int 56: 717-723, 2006.

36. Paschoal JP, Bernardo V, Canedo NH, Ribeiro OD, Caroli-Bottino A and Pannain VL: Microvascular density of regenerative nodule to small hepatocellular carcinoma by automated analysis using CD105 and CD34 immunoexpression. BMC Cancer 14: 72, 2014.

37. Tanaka F, Otake Y, Yanagihara K, Kawano Y, Miyahara R, Li M, Yamada T, Hanaoka N, Inui K and Wada H: Evaluation of angiogenesis in non-small cell lung cancer: Comparison between anti-CD34 antibody and anti-CD105 antibody. Clin Cancer Res 7: 3410-3415, 2001.

38. Wikström P, Lissbrant IF, Stattin P, Egevad L and Bergh A: Endoglin (CD105) is expressed on immature blood vessels and is a marker for survival in prostate cancer. Prostate 51: 268-275, 2002.

39. Yang W, Zhang Y, Fu Z, Sun X, Mu D and Yu J: Imaging proliferation of ${ }^{18} \mathrm{~F}$-FLT PET/CT correlated with the expression of microvessel density of tumour tissue in non-small-cell lung cancer. Eur J Nucl Med Mol Imaging 39: 1289-1296, 2012. 